\title{
Infrared spectroscopy of hydrous glasses of arc magma compositions
}

\author{
Shigeru Yamashita, TOShIHIRo Kitamura and MinORU KuSAKabe \\ Institute for Study of the Earth's Interior, Okayama University, Misasa, Tottori 682-01, Japan
}

(Received June 27, 1996; Accepted December 20, 1996)

\begin{abstract}
Molar absorption coefficients of water in glasses of arc magma compositions have been determined for $\sim 2.8 \mu \mathrm{m}, \sim 2.2 \mu \mathrm{m}$, and $\sim 1.9 \mu \mathrm{m}$ bands. Excellent agreement was found between the water contents calculated from the absorption peak heights and those determined by $\mathrm{H}_{2}$ manometry when the following molar absorption coefficients $\left(\mathrm{m}^{3} / \mathrm{mol} \mathrm{m}\right)$ are used for different glass compositions: $\varepsilon_{2.8 \mu \mathrm{m}}=6.4 \pm 0.1, \varepsilon_{2.2 \mu \mathrm{m}}$ $=0.085 \pm 0.007$, and $\varepsilon_{1.9 \mu \mathrm{m}}=0.084 \pm 0.006$ for tholeiite and high-Al basalt glasses; $\varepsilon_{2.8 \mu \mathrm{m}}=6.8 \pm 0.1$, $\varepsilon_{2.2 \mu \mathrm{m}}=0.094 \pm 0.006$, and $\varepsilon_{1.9 \mu \mathrm{m}}=0.16 \pm 0.03$ for dacite glass. With IR spectroscopy using these coefficients, water concentrations up to $\sim 3 \mathrm{wt} . \%$ in the arc basalt and dacite glasses can be determined accurately.
\end{abstract}

\section{INTRODUCTION}

In the last decade, infrared (IR) spectroscopy has become a powerful analytical tool for water in volcanic glass (e.g., Stolper, 1982; Ihinger et al., 1994). Infrared absorption bands of common geological use are $\sim 2.8 \mu \mathrm{m}$ (fundamental stretching modes of molecular $\mathrm{H}_{2} \mathrm{O}$ and structurally bound $\mathrm{OH}$ ), $\sim 2.2 \mu \mathrm{m}$ (combination stretching + bending mode of structurally bound $\mathrm{OH}$ ), and $\sim 1.9$ $\mu \mathrm{m}$ (combination stretching + bending mode of molecular $\mathrm{H}_{2} \mathrm{O}$ ). The absorption peak heights of these three bands obey the Lambert-Beer's law and hence are usable to determine water concentrations in volcanic glasses. This is true if the glass compositions except for water remain unchanged; the molar absorption coefficients of these three bands display a strong composition-dependence (Ihinger et al., 1994). In the quantitative use of IR spectroscopy, it is thus imperative to calibrate the molar absorption coefficients for glass with the composition of interest. The calibrated sets of the molar absorption coefficients are available for glasses of a limited range of compositions, however (rhyolite glass: Newman et al., 1986; Dobson et al., 1989; Silver et al., 1990; MORB glass:
Dixon et al., 1995).

The purpose of this study is to demonstrate new sets of the molar absorption coefficients of $\sim 2.8 \mu \mathrm{m}, \sim 2.2 \mu \mathrm{m}$, and $\sim 1.9 \mu \mathrm{m}$ bands for a series of hydrous glasses of natural arc magma compositions; tholeiite basalt, high-Al basalt, and dacite. These compositions were chosen because an essential role of water in the evolution and transportation of arc magmas has been repeatedly proposed (e.g., Gill, 1981). The results can be applied to water analysis of natural glass samples from arc volcanoes.

\section{Experimental Procedures}

\section{Synthesis of hydrous glasses}

A series of hydrous glasses of arc magma compositions was synthesized for the present study (Table 1). Three starting materials $(\# 43 \mathrm{gm}=$ tholeiite basalt, Izu-Oshima 1986 ejecta; JB3 = highAl basalt standard, Geological Survey of Japan; JA1 = dacite standard, Geological Survey of Japan), were finely ground in an agate mortar in acetone and heated at $900^{\circ} \mathrm{C}$ under $\log f_{\mathrm{O}_{2}}=\sim-11$. Their anhydrous compositions are given in Table 2. These anhydrous powders were sealed in either 
Table 1. Synthesized hydrous glasses

\begin{tabular}{lcccccc}
\hline No. & Starting material (a) & $\begin{array}{c}P \\
(\mathrm{MPa})\end{array}$ & $\begin{array}{c}T \\
\left({ }^{\circ} \mathrm{C}\right)\end{array}$ & $\begin{array}{c}\text { Duration } \\
(\mathrm{min})\end{array}$ & $\begin{array}{c}\text { Density } \\
\left(\mathrm{kg} / \mathrm{m}^{3}\right)\end{array}$ & $\begin{array}{c}\text { Water }^{(\mathrm{d})} \\
(\mathrm{wt} \%)\end{array}$ \\
\hline $0601 / 3$ & $\# 43 \mathrm{gm}$ & 180 & 1200 & 1680 & 2800 & 0.74 \\
$1127 / 1$ & \#43gm & 196 & 1200 & 720 & 2780 & 1.70 \\
$0627 / 1$ & \#43gm & 180 & 1200 & 1080 & 2790 & 2.03 \\
$0627 / 2$ & \#43gm & 180 & 1200 & 1080 & 2750 & 3.04 \\
$3004 / 2$ & $\mathrm{JB3}$ & 1200 & 1400 & 100 & 2790 & 1.06 \\
3001 & $\mathrm{JB3}$ & 1200 & 1400 & 120 & $2790^{(\mathrm{c})}$ & 1.37 \\
3002 & $\mathrm{JB3}$ & 1100 & 1400 & 50 & $2770^{(\mathrm{c})}$ & 2.09 \\
$3005 / 2$ & $\mathrm{JB3}$ & 1200 & 1500 & 60 & $2740^{(\mathrm{c})}$ & 3.70 \\
$1127 / 3$ & $\mathrm{JA1}$ & 1000 & 1300 & 360 & 2530 & 1.40 \\
$0313 / 1$ & $\mathrm{JA1}$ & 1000 & 1300 & 280 & 2580 & 1.50 \\
$0313 / 4$ & $\mathrm{JA1}$ & 1000 & 1300 & 100 & $2550^{(\mathrm{c})}$ & 2.09 \\
$0313 / 2$ & $\mathrm{JA1}$ & 1000 & 1300 & 100 & 2540 & $2.32^{(\mathrm{c})}$ \\
$1127 / 4$ & $\mathrm{JA1}$ & 1000 & 1300 & 360 & $2490^{(\mathrm{c})}$ & 2.87 \\
$0313 / 3$ & $\mathrm{JA1}$ & 1000 & 1300 & 280 & 2480 & 2.97 \\
\hline
\end{tabular}

Notes:

(a) Anhydrous compositions of the starting materials are given in Table 2.

${ }^{(b)}$ Density determined in toluene based on the Archimedes principle.

(c) Density estimated by an interpolation.

(d) Water content determined by $\mathrm{H}_{2}$ manometry.

${ }^{(e)}$ Water content calculated from the amount of water added to the anhydrous powder.

Au25Pd or Fe-saturated Pt capsules together with known amounts of deionized water. The capsules were held at temperatures above the liquidus of the starting material-water systems $\left(1200 \sim 1500^{\circ} \mathrm{C}\right)$ under pressures for desired durations, and then quenched to temperatures lower than $300^{\circ} \mathrm{C}$ in a few seconds. The low pressure runs $(<200 \mathrm{MPa})$ were carried out using an internally heated gas pressure vessel equipped with a rapid quench device (KOBELCO Co.). The high pressure runs $(>1000 \mathrm{MPa})$ were carried out with a BoydEngland type piston cylinder apparatus. After quenching, the capsules were carefully opened and examined under an optical microscope. The run products were glasses with neither of crystals, bubbles, nor free water fluids.

\section{$\mathrm{H}_{2}$ manometry}

Water concentrations in the synthesized glasses were determined with $\mathrm{H}_{2}$ manometry on the basis of the Suzuoki and Epstein (1976)'s method (Table 1). A fraction of $10-30 \mathrm{mg}$ of individual run products was crashed to small fragments of 0.1 $1.0 \mathrm{~mm}$ in size. These glass fragments were loaded
Table 2. Anhydrous compositions of starting materials*

\begin{tabular}{lrrr}
\hline & Tholeiite basalt & High-Al basalt & Dacite \\
& & & \\
& $\# 43 \mathrm{gm}$ & JB3 & JA1 \\
\hline $\mathrm{SiO}_{2}$ & 53.59 & 51.84 & 65.42 \\
$\mathrm{TiO}_{2}$ & 1.23 & 1.39 & 0.86 \\
$\mathrm{Al}_{2} \mathrm{O}_{3}$ & 14.05 & 17.08 & 15.26 \\
$\mathrm{FeO}^{* * *}$ & 12.59 & 10.20 & 6.08 \\
$\mathrm{MnO}$ & 0.22 & 0.18 & 0.15 \\
$\mathrm{MgO}$ & 5.26 & 5.32 & 1.57 \\
$\mathrm{CaO}$ & 10.41 & 10.00 & 5.73 \\
$\mathrm{Na} \mathrm{O}_{2} \mathrm{O}$ & 2.06 & 2.87 & 3.98 \\
$\mathrm{~K}_{2} \mathrm{O}$ & 0.43 & 0.79 & 0.78 \\
$\mathrm{P}_{2} \mathrm{O}_{5}$ & 0.16 & 0.33 & 0.17 \\
\hline
\end{tabular}

Notes:

*Electron microprobe analysis of the glasses synthesized at $1 \mathrm{GPa}, 1400^{\circ} \mathrm{C}$ under anhydrous conditions.

**Total iron as $\mathrm{FeO}$.

into a reaction vessel (a Pt crucible suspended in a sealed quartz-glass tube) in a desiccated chamber. Water was extracted from the glasses with a step-wise heating method. The glasses were first heated under vacuum at $\sim 150^{\circ} \mathrm{C}$ for 2 hours to remove any adsorbed water, and then fused at 
$\sim 1000^{\circ} \mathrm{C}$ for 20 minutes for complete recovery of the intrinsic water. Only the water extracted at $\sim 1000^{\circ} \mathrm{C}$ was purified cryogenically and converted to $\mathrm{H}_{2}$ in a $\mathrm{U}$ furnace at $\sim 700^{\circ} \mathrm{C}$. The $\mathrm{H}_{2}$ was finally collected into a constant volume with a Toepler pump for the manometric measurement. The accuracy of the water contents obtained was better than \pm 0.1 wt. $\%$.

\section{Micro-IR spectroscopy}

Several fragments of the glasses were taken from different positions of each run product. The glass fragments were mounted in orthodontic resin (L. D. Caulk Co.) and doubly polished to desired thickness. The IR absorption spectra were obtained with a Janssen Fourier transform IR spectrometer (JASCO Co.). The spectrometer is composed of an IR microscope, a $\mathrm{HgCdTe}_{2}$ detector, a Ge beam splitter, a Glover lamp as mid IR source, a W lamp as near IR source, and a beam path continuously purged with dry air. The IR beam was aimed at the area of $0.01 \mathrm{~mm}^{2}$ of an individual sample by adjusting an aperture window and 256 scans were performed. The spectra obtained were stored as digital data for later quantitative data processing.

To apply the Lambert-Beer's law, we need density and thickness of each sample (Eqs. (1) and (2) which appear later). Sample density was determined using the Archimedes principle in toluene with an accuracy of $\pm 50 \mathrm{~kg} / \mathrm{m}^{3}$ (Table 1). Sample thickness was measured with a Litematic 318 digital micrometer (Mitsutoyo Co.) with an accuracy of $\pm 2 \mu \mathrm{m}$. The thickness was reduced to $30-100 \mu \mathrm{m}$ for the analysis of mid IR region (2.5$25 \mu \mathrm{m}$ in wave length) and $100-300 \mu \mathrm{m}$ for the analysis of near IR region $(<2.5 \mu \mathrm{m}$ in wave length). The absorbance obtained under these conditions was less than 2 at the bands of interest, which ensures a good reproducibility of the absorbance measurement.

\section{Quantitative Data Processing}

Figure 1 shows a typical IR spectrum obtained in this study. The IR absorption bands of dissolved water species have already been assigned for a variety of hydrous silicate glasses (e.g., Stolper, 1982; Silver and Stolper, 1989; Dixon et al., 1995). According to their band assignment, a mid IR band observed at $\sim 2.8 \mu \mathrm{m}$ is attributed to the fundamental stretching mode of molecular $\mathrm{H}_{2} \mathrm{O}$ and structurally bound $\mathrm{OH}$. Near IR bands at $\sim 2.2$ $\mu \mathrm{m}$ and $\sim 1.9 \mu \mathrm{m}$ are due to the combination stretching + bending mode of structurally bound $\mathrm{OH}$ and the combination stretching + bending mode of molecular $\mathrm{H}_{2} \mathrm{O}$, respectively. Broad peaks observed in the near IR region are attributed to absorption by iron; one centered at $\sim 1.8 \mu \mathrm{m}$ and one centered at $\sim 1.0 \mu \mathrm{m}$ (Rossman, 1988; Dixon et al., 1995).

Water concentration (total water species as $\mathrm{H}_{2} \mathrm{O}$ ) in glass is given by the expressions analogous to the Lambert-Beer's law (e.g., Stolper, 1982):

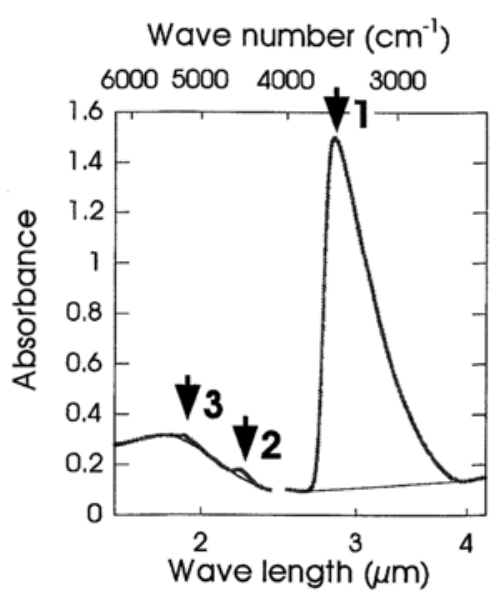

Fig. 1. Typical IR spectrum of the hydrous glass synthesized in this study (No. 1127/1: tholeiite basalt glass containing $1.7 \mathrm{wt} . \%$ of water; sample thickness $=0.085$ $\mathrm{mm}$ for the measurement of mid IR region, $0.221 \mathrm{~mm}$ for the measurement of near IR region). Arrows indicate individual absorption bands assigned to vibration of dissolved water species $(1=\sim 2.8 \mu \mathrm{m}$ band due to the fundamental stretching of molecular $\mathrm{H}_{2} \mathrm{O}$ and structurally bound $\mathrm{OH}, 2=\sim 2.2 \mu \mathrm{m}$ band due to the combination stretching-bending of structurally bound $\mathrm{OH}$, and $3=\sim 1.9 \mu \mathrm{m}$ band due to the combination stretching-bending of molecular $\mathrm{H}_{2} \mathrm{O}$ ). Background spectrum calculated is also superimposed with a thin line. 


$$
C_{\text {water }}=100 \times \frac{0.01802 a b s_{2.8 \mu \mathrm{m}}}{d \rho \varepsilon_{2.8 \mu \mathrm{m}}},
$$

when the $\sim 2.8 \mu \mathrm{m}$ band is used, and

$$
C_{\text {water }}=100 \times \frac{0.01802}{d \rho}\left(\frac{a b s_{2.2 \mu \mathrm{m}}}{\varepsilon_{2.2 \mu \mathrm{m}}}+\frac{a b s_{1.9 \mu \mathrm{m}}}{\varepsilon_{1.9 \mu \mathrm{m}}}\right) \text {, }
$$

when the $\sim 2.2 \mu \mathrm{m}$ and $\sim 1.9 \mu \mathrm{m}$ bands are used. In the above equations, $C_{\text {water }}$ is water concentration (wt.\%), $d$ is sample thickness (m), $\rho$ is sample density $\left(\mathrm{kg} / \mathrm{m}^{3}\right), a b s_{2.8 \mu \mathrm{m}}, a b s_{2.2 \mu \mathrm{m}}, a b s_{1.9 \mu \mathrm{m}}$ are absorption peak heights of individual bands (absorbance), and $\varepsilon_{2.8 \mu \mathrm{m}}, \varepsilon_{2.2 \mu \mathrm{m}}, \varepsilon_{1.9 \mu \mathrm{m}}$ are molar absorption coefficients of individual bands $\left(\mathrm{m}^{3} / \mathrm{mol}\right.$ $\mathrm{m})$. The absorption peak heights were determined by subtracting appropriate background spectra interpolated from the neighboring regions (Fig. 1). In the mid IR region, a linear tangent at $\sim 4.0 \mu \mathrm{m}$ and $\sim 2.7 \mu$ m adequately represents the background of the $\sim 2.8 \mu \mathrm{m}$ band. In the NIR region, sum of the two Gaussian peaks, one at $\sim 1.8 \mu \mathrm{m}$ and another at $\sim 1.0 \mu \mathrm{m}$, was fitted to the broad background of $\sim 2.2 \mu \mathrm{m}$ and $\sim 1.9 \mu \mathrm{m}$ bands with the non-linear least square method. Reproducibility of the peak height measurement of these three bands was as good as \pm 0.01 for the absorbance of 1-2 and \pm 0.001 for the absorbance less than 1 .

Equating the right-hand side of Eq. (1) or Eq. (2) to the water content determined by $\mathrm{H}_{2}$ manometry, we calibrated the molar absorption coefficients of the $\sim 2.8 \mu \mathrm{m}, \sim 2.2 \mu \mathrm{m}$, and $\sim 1.9 \mu \mathrm{m}$ bands for the synthesized glasses. The calibration minimizes the $\chi$-square of Eq. (1) or Eq. (2) for the glass of interest, thereby yielding a unique set of the molar absorption coefficients. Each datum is weighted by the analytical error, which stems from propagation of the uncertainties in thickness, density, and absorption peak height.

\section{Results AND DISCUSSION}

Figure 2 shows the results of the calibration for the synthesized glasses. Excellent agreement is found between the water contents calculated from IR absorption and the water contents determined by $\mathrm{H}_{2}$ manometry when the following molar absorption coefficients are adopted: $\varepsilon_{2.8 \mu \mathrm{m}}=6.4$ $\pm 0.1(1 \sigma) \mathrm{m}^{3} / \mathrm{mol} \mathrm{m}, \varepsilon_{2.2 \mu \mathrm{m}}=0.085 \pm 0.007 \mathrm{~m}^{3} /$ $\mathrm{mol} \mathrm{m}$, and $\varepsilon_{1.9 \mu \mathrm{m}}=0.084 \pm 0.006 \mathrm{~m}^{3} / \mathrm{mol} \mathrm{m}$ for the tholeiite basalt and high-Al basalt glasses; $\varepsilon_{2.8 \mu \mathrm{m}}=6.8 \pm 0.1 \mathrm{~m}^{3} / \mathrm{mol} \mathrm{m}, \varepsilon_{2.2 \mu \mathrm{m}}=0.094 \pm$ $0.006 \mathrm{~m}^{3} / \mathrm{mol} \mathrm{m}$, and $\varepsilon_{1.9 \mu \mathrm{m}}=0.16 \pm 0.03 \mathrm{~m}^{3} / \mathrm{mol}$ $\mathrm{m}$ for the dacite glass. In this calibration, we assumed that the molar absorption coefficients do not change between the tholeiite basalt and high$\mathrm{Al}$ basalt glasses. This assumption is rationalized because the calibration errors for these two basalt glasses are small as much as those for the dacite glass of a single composition. The calibration errors of the $\varepsilon_{2.8 \mu \mathrm{m}}$ and $\varepsilon_{1.9 \mu \mathrm{m}}$ values are greater than those of the $\varepsilon_{2.8 \mu \mathrm{m}}$ values, which difference arises from the presence of multicolinearity between the $a b s_{2.2 \mu \mathrm{m}}$ and $a b s_{1.9 \mu \mathrm{m}}$ values.

According to the present results, we infer that each of the arc basalt and dacite glasses defines a unique set of the $\varepsilon_{2.8 \mu \mathrm{m}}, \varepsilon_{2.2 \mu \mathrm{m}}$ and $\varepsilon_{1.9 \mu \mathrm{m}}$ values, within the range of water concentrations up to 3.7 wt.\% for the arc basalt glasses and up to $3.0 \mathrm{wt} . \%$ for the dacite glass (Fig. 2). The obtained molar absorption coefficients can be applied to IR spectroscopy of water in the volcanic glasses of those compositions. Yet, at the $\sim 2.8 \mu \mathrm{m}$ band, determination of water contents greater than $\sim 3$ wt. \% may include error of $\sim \pm 10 \%$ regardless of the availability of the well-determined $\varepsilon_{2.8 \mu \mathrm{m}}$ values $(\sim \pm 2 \%)$. Such a high concentration of water, together with strong absorption of this band (Fig. $1)$, requires extremely small sample thickness $(<50$ $\mu \mathrm{m})$ to ensure good reproducibility of the absorbance measurement. Thickness smaller than $50 \mu \mathrm{m}$ is difficult to measure accurately, however, and the resultant uncertainty in sample thickness exceeds any of the other uncertainties (Fig. 2). At the $\sim 2.2 \mu \mathrm{m}$ and $\sim 1.9 \mu \mathrm{m}$ bands, such situation is relieved by weak absorption of these bands (Fig. 1), still the improvement of the analytical accuracy is limited by the relatively large errors of the $\varepsilon_{2.2 \mu \mathrm{m}}$ and $\varepsilon_{1.9 \mu \mathrm{m}}$ values (up to $\sim \pm 20 \%$ ) when these bands are used to discriminate concentrations of 

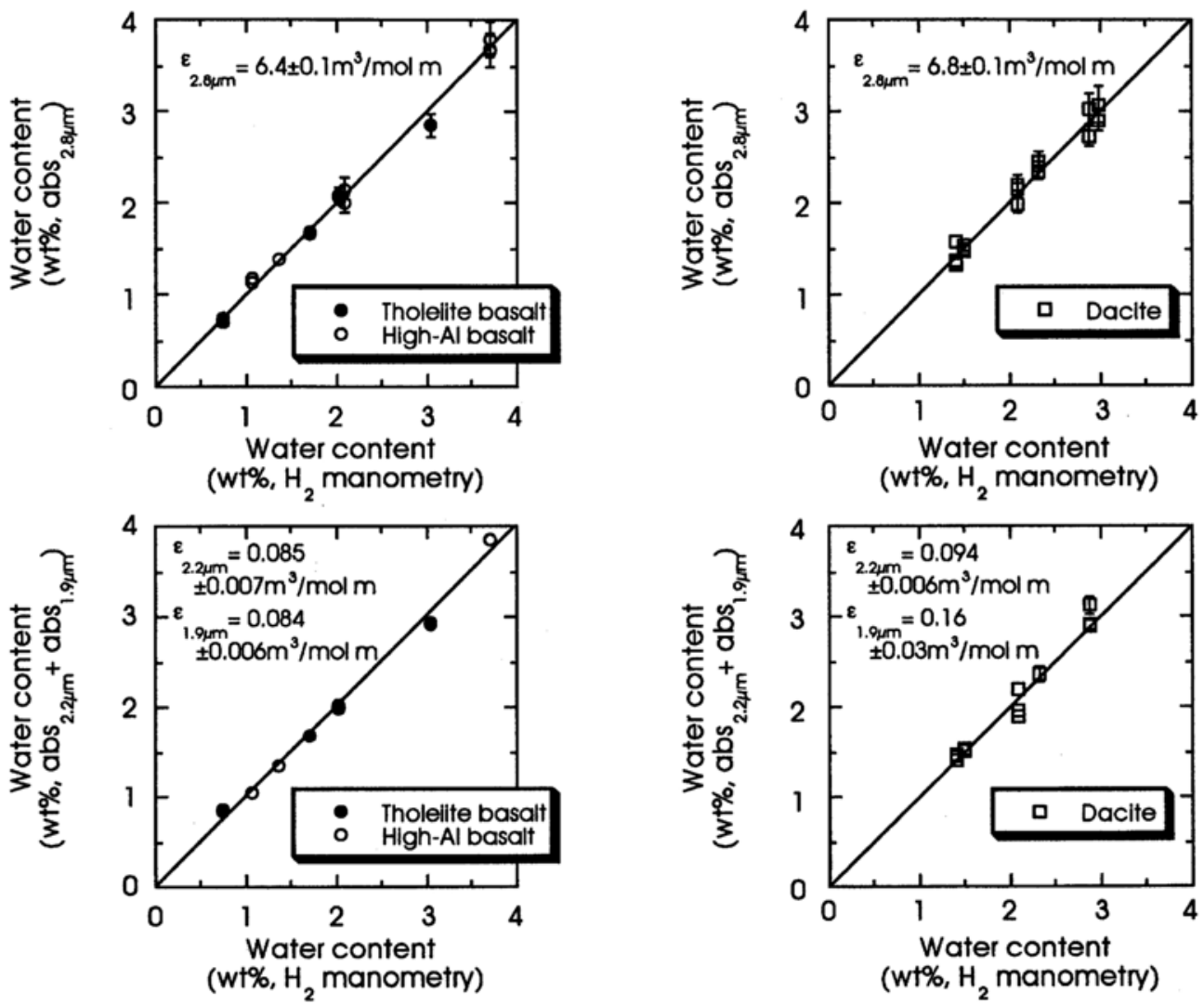

Fig. 2. Water contents calculated from IR absorption are compared with water contents determined by $\mathrm{H}_{2}$ manometry. Also shown are the molar absorption coefficients $(\varepsilon)$ determined for the present data set. Error bars represent propagation of the uncertainties in thickness, density, and absorption peak height of individual sample. The analytical error of the $\mathrm{H}_{2}$ manometry is as small as the size of the symbols.

Table 3. Molar absorption coefficients of $\sim 2.8 \mu \mathrm{m}, \sim 2.2 \mu \mathrm{m}$, and $\sim 1.9 \mu \mathrm{m}$ bands for a variety of hydrous silicate glasses

\begin{tabular}{lcccccc}
\hline & $\mathrm{SiO}_{2}$ (wt\%) & Water $(\mathrm{wt} \%)$ & \multicolumn{2}{c}{ Molar absorption coefficients* $\left(\mathrm{m}^{3} / \mathrm{mol} \mathrm{m}\right)$} & Ref. \\
\cline { 3 - 5 } & & & $\varepsilon_{2.8 \mu \mathrm{m}}$ & $\varepsilon_{2.2 \mu \mathrm{m}}$ & $\varepsilon_{1.9 \mu \mathrm{m}}$ \\
\hline High-Al basalt & 51.84 & $1.06 \sim 3.70$ & $6.4 \pm 0.1$ & $0.085 \pm 0.007$ & $0.084 \pm 0.006$ & 1 \\
Tholeiite basalt & 53.59 & $0.74 \sim 3.04$ & & & \\
Dacite & 65.42 & $1.40 \sim 2.97$ & $6.8 \pm 0.1$ & $0.094 \pm 0.006$ & $0.16 \pm 0.03$ & 1 \\
MORB & 50.72 & $0.37 \sim 2.49$ & $6.3 \pm 0.3$ & $0.067 \pm 0.003$ & $0.062 \pm 0.007$ & 2 \\
Albite & 68.05 & $1.02 \sim 6.83$ & $7.0 \pm 0.2$ & $0.113 \pm 0.004$ & $0.167 \pm 0.006$ & 3 \\
Rhyolite & 77.59 & $0.09 \sim 0.18$ & $8.8 \pm 0.8$ & - & - & 4 \\
Rhyolite & 77.58 & $<\sim 4$ & - & $0.173 \pm 0.002$ & $0.161 \pm 0.005$ & 5 \\
\hline
\end{tabular}

Notes:

1 = This study, 2 = Dixon et al. (1995), 3 = Silver and Stolper (1989), 4 = Dobson et al. (1989), 5 = Silver et al. (1990).

*Errors $(1 \sigma)$ of the molar absorption coefficients were estimated by the variance-covariance matrix method (Reid et al., 1973). 
individual water species $\left(\mathrm{H}_{2} \mathrm{O}\right.$ and $\left.\mathrm{OH}\right)$ from each other.

Comparing the present results with previous works (Table 3 ), we note that the $\varepsilon_{2.8 \mu \mathrm{m}}$ value obtained for the arc basalt glasses is only $2 \%$ greater than the value reported for the MORB glass by Dixon et al. (1995). Such a small variation in the $\varepsilon_{2.8 \mu \mathrm{m}}$ values among the glasses of similar $\mathrm{SiO}_{2}$ content is rather comparable to the magnitude of the calibration errors of the $\varepsilon_{2.8 \mu \mathrm{m}}$ values. Moreover, the $\varepsilon_{2.8 \mu \mathrm{m}}$ value determined for the dacite glass is only $3 \%$ smaller than that reported for the albite glass by Silver and Stolper (1989), regardless of substantial compositional differences between them except $\mathrm{SiO}_{2}$. The use of a common $\varepsilon_{2.8 \mu \mathrm{m}}$ value may thus be good approximation for silicate glasses with similar $\mathrm{SiO}_{2}$ content. The $\varepsilon_{2.2 \mu \mathrm{m}}$ and $\varepsilon_{1.9 \mu \mathrm{m}}$ values, on the other hand, show substantial composition-dependence even among the glasses having practically the same $\varepsilon_{2.8 \mu \mathrm{m}}$ (Table 3). The use of $\sim 2.2 \mu \mathrm{m}$ and $\sim 1.9 \mu \mathrm{m}$ bands for water analysis is thus unreliable unless the molar absorption coefficients are available for the glass of interest.

Acknowledgments-We are grateful to Yukihiro Matsuhisa and an anonymous reviewer for their critical reading of the manuscript. We also thank Yoshie Ogo for her assistance in operation of the IR spectrometer. This study was supported by a Grant-in-Aid for Scientific Research (No. 06403003) from the Ministry of Education, Science and Culture of Japan to M. K. and S. Y.

\section{REFERENCES}

Dixon, J. E., Stolper, E. M. and Holloway, J. R. (1995) An experimental study of water and carbon dioxide solubilities in mid-ocean ridge basaltic liquids. Part I: calibration and solubility models. J. Petrol. 36, 1607-1631.

Dobson, P. F., Epstein, S. and Stolper, E. M. (1989) Hydrogen isotope fractionation between coexisting vapor and silicate glasses and melts at low pressure. Geochim. Cosmochim. Acta 53, 2723-2730.

Gill, J. B. (1981) Orogenic Andsites and Plate Tectonics. Springer, Berlin, Heidelberg, New York.

Ihinger, P. D., Hervig, R. L. and McMillan, P. F. (1994) Analytical methods for volatiles in glasses. Volatiles in Magmas (Carroll, M. R. and Holloway, J. R., eds.), Rev. Mineral. 30, 67-121.

Newman, S., Stolper, E. M. and Epstein, S. (1986) Measurement of water in rhyolitic glasses: calibration of an infrared spectroscopic technique. Amer. Mineral. 71, 1527-1541.

Reid, M. J., Gancarz, A. J. and Albee, A. L. (1973) Constrained least-squares analysis of petrologic problems with an application to Lunar sample 12040. Earth Planet. Sci. Lett. 17, 433-445.

Rossman, G. R. (1988) Optical spectroscopy. Spectroscopic Methods in Mineralogy and Geology (Hawthorne, F. C., ed.), Rev. Mineral. 18, 207-243.

Silver, L. and Stolper, E. (1989) Water in albitic glasses. J. Petrol. 30, 667-709.

Silver, L. A., Ihinger, P. D. and Stolper, E. (1990) The influence of bulk composition on the speciation of water in silicate glasses. Contrib. Mineral. Petrol. 104, 142-162.

Stolper, E. (1982) Water in silicate glasses: an infrared spectroscopic study. Contrib. Mineral. Petrol. 81, 117.

Suzuoki, T. and Epstein, S. (1976) Hydrogen isotope fractionation between $\mathrm{OH}$-bearing minerals and water. Geochim. Cosmochim. Acta 40, 1229-1240. 